\title{
Assessing Parameters for Computations in Rock Mechanics
}

\author{
P.J.N. Pells Pells Sullivan Meynink Pty Ltd, Australia
}

\begin{abstract}
Estimation of rock mass stiffness and shear strength parameters is fundamental to the validity of most applied mechanics calculations for rock mechanics design purposes. Estimation of such parameters is very difficult and has to be based on rock mass characterisation. Currently the Hoek-Brown approach using GSI is widely used for assessing stiffness and shear strength parameters. However, there appear to be few test data to support the parameters determined using this method. This paper presents case studies for both rock mass modulus and rock mass shear strength in an attempt to assess the validity of the approach of using GSI and the Hoek-Brown criterion. It is concluded that for some rock masses the method works well, but in other cases can give very misleading assessments of stiffness and shear strength parameters. It is also concluded that further work is required in collecting and analysing good case studies in order to provide guidelines for the profession.
\end{abstract}

\section{Introduction}

In a paper presented earlier this year to the Sixth International Symposium on Ground Support in Mining and Civil Engineering Construction, the author presented his reservations in respect to the direction being taken by practitioners in rock mechanics and engineering geology (Pells, 2008). The gist of the paper is summarised by its abstract which is as follows:
"A good thing is becoming a bad thing. Rock mass classification systems, that are so excellent for communications between engineers and geologists, and that can be valuable in categorising project experience, are emasculating engineering geology and rock mechanics. Some engineering geologists have been sucked in to thinking that $Q$ and $R M R$ values are all that is needed for engineering purposes, and seem to have put aside what can be learned from structural geology and geomorphology. Many rock mechanics engineers seem to have forgotten the scientific method. This paper attempts to redress the situation by showing how mechanics can be used in rock engineering to design with a similar rigor to that used in the fields of structural engineering, hydraulics and soil mechanics. It also attempts to remind practitioners of what can be achieved by skilled engineering geology."

Along a similar vein, Palmstrom and Broch presented a paper in 2006 expressing certain reservations regarding the use of rock mass classification systems (Palmstrom and Broch, 2006). Arising out of that paper Pells and Bertuzzi (2008) submitted a discussion based on factual data from 13 major tunnels and caverns, ten of which are in Sydney, two in Melbourne and one in Brisbane. The conclusion from those case studies is encapsulated in the following paragraph from the published discussion:
"Over the past 15 years we have collected data from many of the major civil engineering tunnel and cavern projects in Australia. This information has caused us concern in regard to the application of Barton's Q-system and Bieniawski's RMR system in support design, because there is clear evidence that the support deduced from the classification system may be substantially non- conservative. In this discussion we provided the factual information that has lead to our concern and to our recommendations that these classification systems should not be used for anything other than feasibility level assessments."

Not everyone agrees with the above views, but from the feedback that has come in from several parts of the world, and from a reading of Goodman's (2007) Riedmüller Memorial Lecture, it is clear that the author is not alone in his concerns.

It is appropriate to turn from criticism to doing something positive about these concerns. This paper is a small step in that direction. 
It is unlikely that the author will be convinced that proper design can be done directly using rock mass classification systems. However, assessment of engineering parameters for analytical design has to be based on some form of rock mass categorisation. Therefore this paper addresses predictions of modulus and strength using rock mass classification as per the Hoek-Brown approach. These parameters are required for applied mechanics design and analysis, of which there are many examples in the literature going back to the pioneering work of people like Muller, Jaeger, Cook, Hoek and Brown. Several examples of design methods using proper applied mechanics are given in the earlier paper this year (Pells, 2008). Notwithstanding the fact that it is a bad principle to repeat material that has already been published, one section from that paper is repeated in Section 2, below, because it represents material which was published some years ago but with errors in some of the equations subsequently picked up by Carter (2003). It is important that this material be properly disseminated in its correct form.

\section{Mechanics of support design in horizontal bedded strata}

\subsection{Scope of application}

In many parts of the world there occur near horizontally bedded strata of sandstones and shales wherein, to depths of several hundred metres, the natural horizontal stresses are higher than overburden pressure. Examples include the Karoo beds of South Africa, the Bunter Sandstone of the UK and the Triassic strata of the Sydney region.

\subsection{Fundamentals}

Analytical studies have shown that in such strata, and in such stress fields, stress concentrations in the crown are smaller with a flat crown shape than with an arch (Figure 1). Furthermore, cutting an arch-shaped crown in this type of rock is counterproductive because this creates unnecessary cantilevers of rock, and fails to utilise positive aspects of a relatively high horizontal stress field (Figure 2).
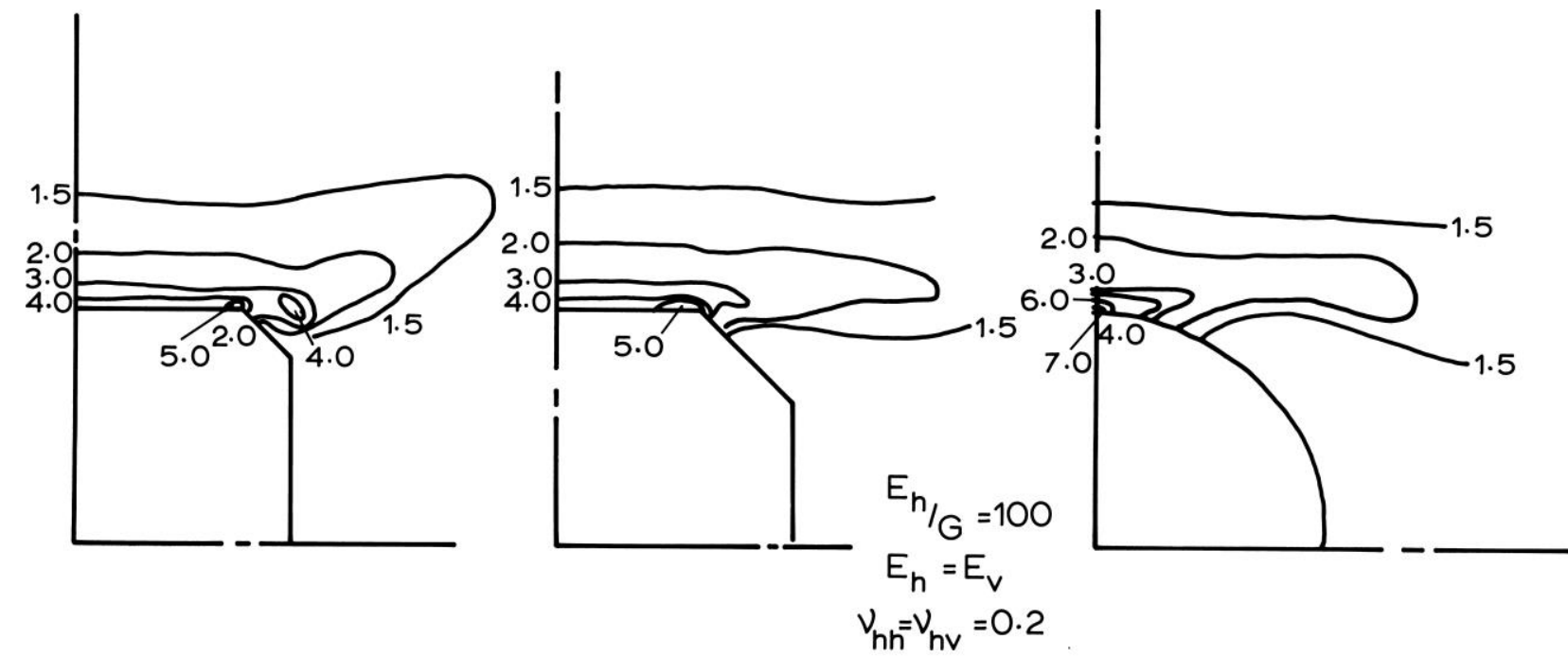

Figure 1 Contours of major principal stress as a function of the virgin horizontal stress field 




Figure 2 Negative impacts of excavating an arch shape in certain horizontally bedded strata

The simple piece of applied mechanics (Evans, 1941) showed that spans in excess of $15 \mathrm{~m}$ can readily be sustained in a typical horizontally bedded sandstone having unconfined compressive strength greater than about $20 \mathrm{MPa}$, provided the effective bedding spacing is greater than $5 \mathrm{~m}$. For strata of other strengths, stiffnesses and natural stress fields the requisite thickness can be calculated using an updated version of Evan's linear arch theory (Sofianos, 1996). The problem is that bedding spacings are typically much less than $5 \mathrm{~m}$, so the trick is to make the rock mass function as if there is the requisite thickness bed overlying the excavation. To do so one has to use reinforcement to reduce bedding plane shear displacements to those that would occur in an equivalent massive beam.

To implement this procedure two initial sets of calculations have to be made.

1. Calculation of the bedding plane shear displacements that would occur, at an acceptable maximum crown sag, if the crown rock were unreinforced. This can be done using a jointed finite element model.

2. Calculate the shear stresses which would occur in an imaginary massive bed of the requisite thickness at the locations of physical bedding horizons. This can be done using the same finite element model but with elastic bedding plane behaviour.

Once the process of calculating the bedding plane shear displacements and shear stresses is completed, attention can be turned to calculating the rockbolt capacities, orientations and distributions required to create the bed of requisite thickness.

\subsection{Calculation of rockbolt capacities}

\subsubsection{Forces}

At the outset it should be noted that consideration is given here only to fully grouted rockbolts. These are typically so far superior to end anchored bolts in their influence on rock mass behaviour that the latter should only be used for local support of isolated loosened blocks of rock.

Figure 3 shows the case of a single rockbolt crossing a discontinuity. The reinforcement acts to increase the shear resistance of the joint by the mechanisms summarised below.

- An increase in shear resistance due to the lateral resistance developed by the rockbolt via dowel action - force $R_{l}$.

- An increase in normal stress as a result of prestressing of the rockbolt - force $R_{2}$.

- An increase in normal stress as a result of axial force developed in the rockbolt from dilatancy of the joint - force $R_{3}$. 
- An increase in normal stress as a result of axial force developed in the rockbolt from lateral extension - force $R_{4}$.

- An increase in shear resistance due to the axial force in the rockbolt resolved in the direction of the joint - force $R_{5}$.

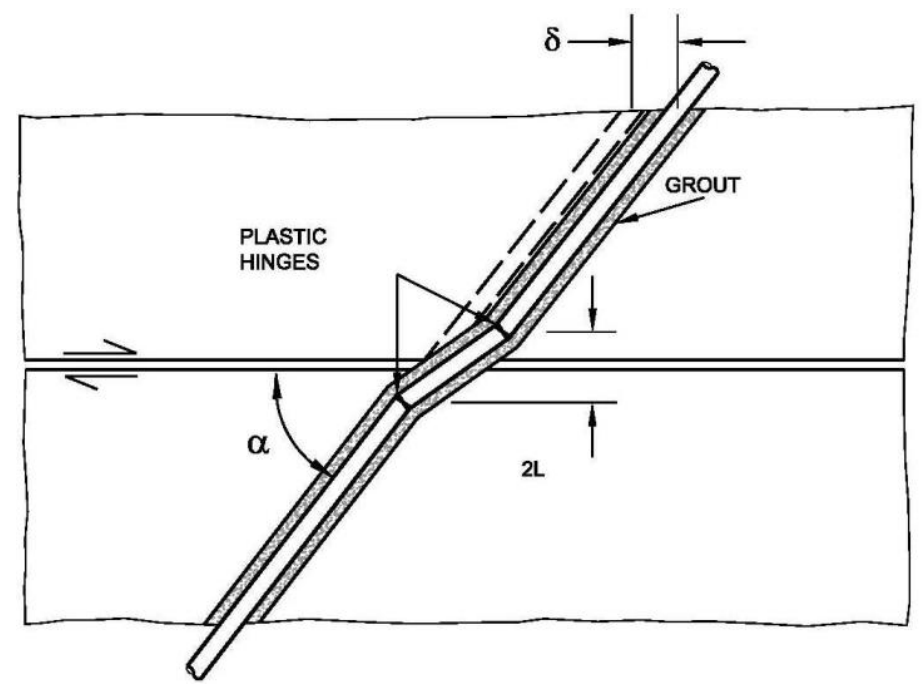

\section{Figure 3 Grouted rockbolt in shear (Dight, 1982)}

Forces $R_{1}$ and $R_{5}$ can be considered as increasing the cohesion component along the joint. The other three components increase the frictional component of joint shear strength by increasing the effective normal stress on the interface. If the rockbolts are at a spacing $S$, so that each bolt affects an area $S^{2}$, the equivalent increases in cohesion, $\Delta_{c}$, and normal effective stress, $\Delta \sigma_{n}$, are as follows:

$$
\begin{gathered}
\Delta c=\frac{R_{1}+R_{5}}{S^{2}} \\
\Delta \sigma_{n}=\frac{R_{2}+R_{3}+R_{4}}{S^{2}}
\end{gathered}
$$

Therefore, the equivalent strength of the joint, $\mathrm{s}_{\mathrm{j}}$ will be as follows:

$$
s_{j}=\left(c_{j}+\Delta c\right)+\left(\sigma_{n 0}+\Delta \sigma_{n}\right) \tan \phi_{j}
$$

Where $c_{j}$ is the effective cohesion of joint, $\phi_{j}$ the effective friction angle of joint, $\sigma_{n 0}$ the initial effective normal stress on joint, $\Delta c$ the equivalent increase in effective cohesion (Equation (2)) and $\Delta \sigma_{n}$ the equivalent increase in effective normal stress (Equation (3)).

Force $R_{2}$ is created by the initial pretension in the bolt, as too is most of the force $R_{5}$. Methods of calculating the forces are detailed in Sections 2.3.2 to 2.3.4 are detailed.

\subsubsection{Calculations of dowel action: Force $R_{I}$}

Calculations of dowel action is based on laboratory test data and theoretical analyses presented by Dight (1982). The experimental data showed that:

- Plastic hinges formed in the fully grouted rockbolts at small shear displacements (typically $<1.5 \mathrm{~mm}$ ); these plastic hinges were located a short distance on either side of the joint.

- Crushing of the grout, or rock (whichever was the weaker) occurred at similar small displacements.

Based on his experiments, on plastic bending theory, and Ladanyi's expanding cylinder theory, Dight (1982) developed equations for calculating the 'dowel' force $R_{l}$. For the simplified assumptions of grout strength 
equal to or less than the rock, and for the joint having no infill, the equations, with corrections by Carter (2003), are:

$$
\mathrm{R}_{1}=\frac{\mathrm{D}^{2}}{4} \sqrt{1.7 \sigma_{\mathrm{y}} \mathrm{P}_{\mathrm{u}} \pi\left[1-\left(\frac{\mathrm{T}}{\mathrm{T}_{\mathrm{y}}}\right)^{2}\right]}
$$

where:

$$
\begin{gathered}
\mathrm{P}_{\mathrm{u}}=\sigma_{\mathrm{c}}\left[\frac{\delta}{\mathrm{K}(\pi \mathrm{D}+2 \delta)}\right]^{\mathrm{A} / 2} \\
A=\frac{2 \sin \phi}{1+\sin \phi} \\
K=\sigma_{c}\left(\frac{1-v^{2}}{E}\right) \ln \left(\frac{\sigma_{c}}{2 p_{o}-\sigma_{t}}\right)+\frac{\sigma_{c}}{2 P_{0}-\sigma_{t}}\left[\frac{2 v\left(P_{o}-\sigma_{t}\right)-\sigma_{t}}{E}\right]
\end{gathered}
$$

and where:

$\sigma_{y}, T_{y}=$ yield stress and yield force in the bolt.

$\sigma_{c} \quad=\quad$ unconfined compressive strength of the rock.

$\sigma_{t} \quad=$ tensile strength of the rock.

$\phi=$ internal angle of friction of the rock.

$v, E=$ elastic constraints of the rock.

$\mathrm{P}_{0}=$ initial stress in the rock in the plane.

$\delta=$ shear displacement of the joint.

$\mathrm{T}=$ initial bolt pretension.

The term in the square brackets in Equation (5) allows for the effect on the plastic moment of the tensile force in the bar.

\subsubsection{Calculation of axial forces due to joint dilation (R3) and due to bolt extension caused by shearing (R4)}

If the assumption is made that in a fully grouted rockbolt the incremental axial strain in the bolt is dominantly between the two plastic hinges (Figure 7) then the normal force generated by dilation is:

$$
R_{3}=\frac{\pi D^{2} E_{s}}{4}\left(\frac{\delta \tan i}{2 L}\right) \sin ^{3} \alpha
$$

Where:

$\alpha=$ angle between bolt and bedding plane.

$i=$ dilation angle.

The axial force due to lengthening is:

$$
\begin{gathered}
R_{4} \Lambda=\frac{\left(\frac{2 L}{\tan \alpha}+\delta\right) \sin \alpha}{2 L \cos \gamma}-1 \\
\gamma=\tan ^{-1}\left(\frac{2 L \tan \alpha}{2 L+\delta \tan \alpha}\right)
\end{gathered}
$$




\subsubsection{Components due to bolt prestressing: forces $R_{2}$ and $R_{5}$}

If a bolt is prestressed to a force $\mathrm{P}_{\text {st }}$ prior to grouting then the normal force on the joint is:

$$
R_{2}=\mathrm{P}_{\mathrm{st}} \sin \left(\alpha-\tan ^{-1}\left(\frac{\delta}{2 L}\right)\right)
$$

and the force along the joint is:

$$
R_{5}=\mathrm{P}_{\mathrm{st}} \cos \left(\alpha-\tan ^{-1}\left(\frac{\delta}{2 L}\right)\right)
$$

Strictly $R_{2}$ should be modified by $R_{3}$ and $R_{4}$ but this is a second order effect.

Equations (9) to (13) presume that rockbolts are inclined so that movements on bedding planes increase their effectiveness.

\subsubsection{Relative importance of the forces $R_{1}$ to $R_{5}$}

Figure 4 shows the contributions of the different rockbolt actions to the shear strength of a typical joint or bedding plane in Hawkesbury Sandstone. The figure shows clearly that at shear displacements of about $2 \mathrm{~mm}$ the contributions from prestress and dowel action are of similar magnitude. The contribution due to elongation is quite small but the contribution from joint dilation can completely dominate the load in the bolt, and with rough joints will rapidly lead to bolt failure.

At this time the author has not explored the relative contributions in strong rock, it could be an illuminating exercise.

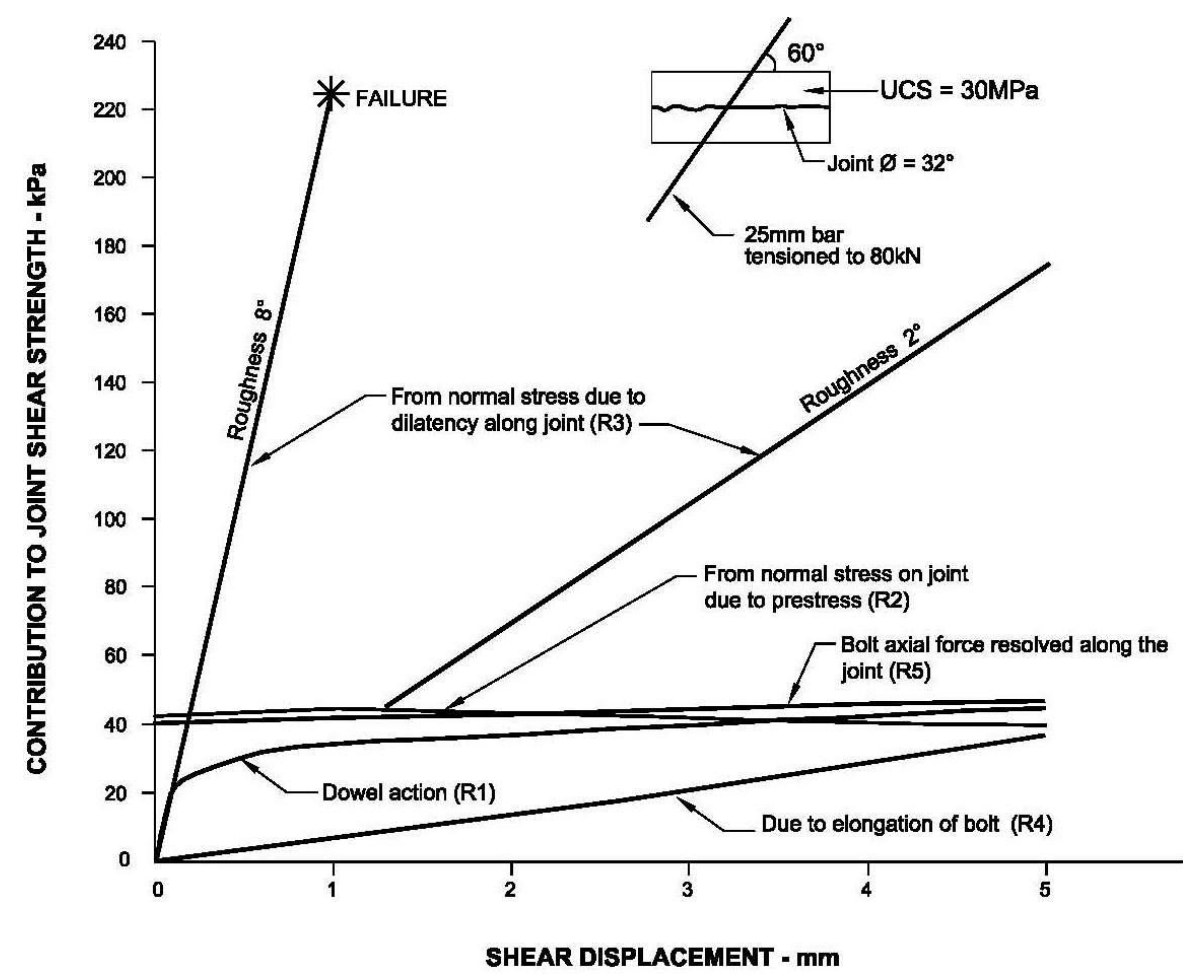

Figure 4 Contribution of the different bolt actions to joint shear strength

\subsection{Design of rockbolt layout to create the requisite linear arch}

\subsubsection{Rockbolt length}

The bolt length is usually taken as the required linear arch thickness plus $1 \mathrm{~m}$. This presumes there to be a physical bedding plane just below the upper surface of the nominated linear arch and is intended to allow sufficient bond length for mobilisation of bolt capacity at this postulated plane. 


\subsubsection{Rockbolt density}

The design process is iterative because of the following variables in regard to the bolts alone:

- Bolt capacity - a function of diameter and bolting material (typically either $400 \mathrm{MPa}$ reinforcing steel, or $950 \mathrm{MPa}$ steel associated with Macalloy/VSL/Diwidag bars).

- Bolt inclination.

- Bolt spacing across and along the tunnel.

Typically, for tunnels of spans up to about $12 \mathrm{~m}$, use is made of standard rockbolt steel (nominally $400 \mathrm{MPa}$ ). For larger spans some, or all, of the bolts comprise high-grade steel, or cable.

It is advantageous to incline bolts across the bedding planes provided one is certain as to the direction of shearing. Bolts inclined across bedding against the direction of shearing can be ineffective. Therefore, given the uncertainty in this regard it is considered appropriate that only those bolts located over the tunnel abutments should be inclined, the central bolts are installed vertically. Figure 5 shows the support used for the wide span section of the Eastern Distributor tunnels in Sydney.

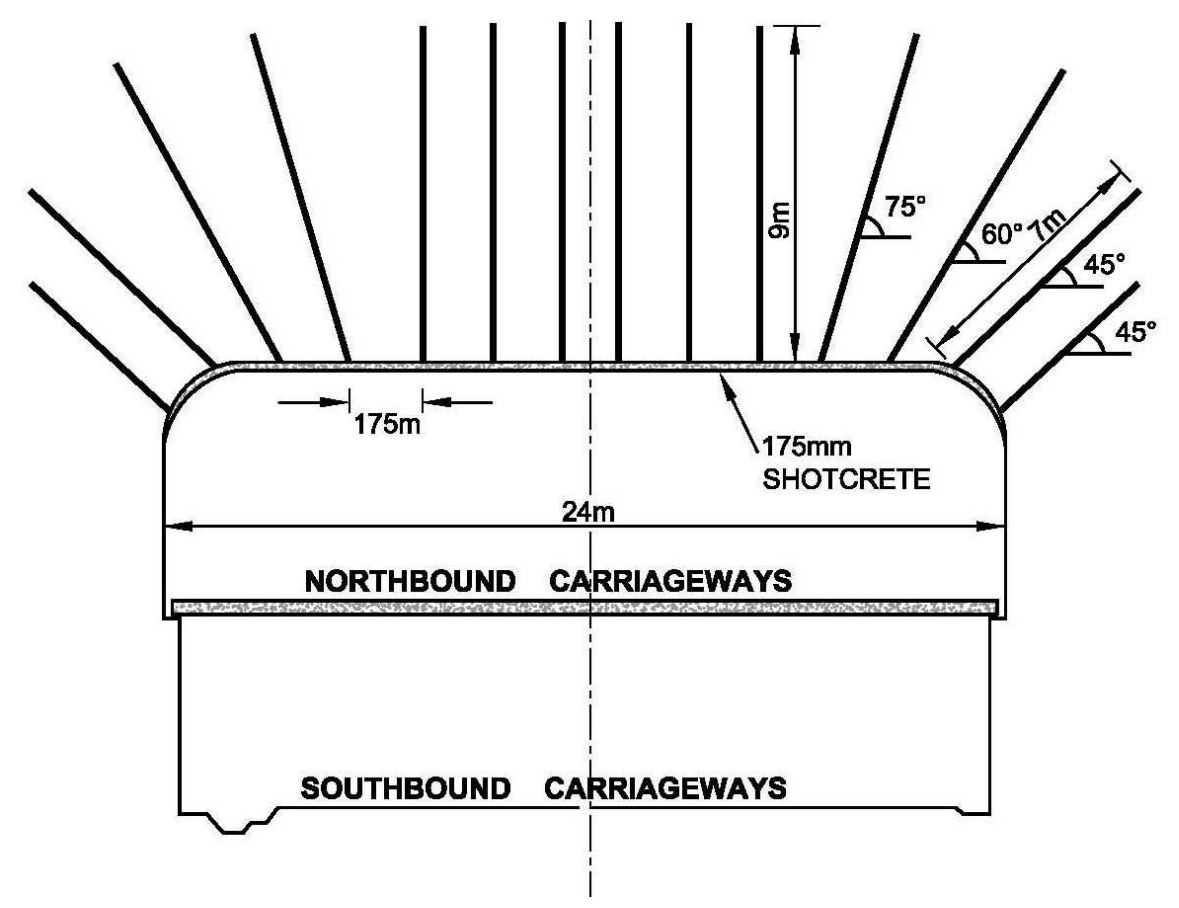

Figure 5 Rockbolt support for $\mathbf{2 4} \mathbf{m}$ span of double decker Eastern Distributor

Having made the above decisions regarding bolt lengths and inclinations, the process of bolt density computation proceeds, in principle, as set out below.

Step 1 The tunnel crown is divided into patches at each bedding horizon with each patch intended to cover one rockbolt. It should be noted that the first major bedding horizon above the crown usually controls design.

Step 2 From the jointed finite element analysis the average shear displacement and the normal stress within each patch are calculated.

Step 3 A rockbolt type (diameter, material, inclination) is selected for a patch and the forces $R_{l}$ to $R_{5}$ are calculated as per the equations given earlier.

Step 4 Using the values of $R_{I}$ to $R_{5}$ and the normal stress from Step 2, the shear strength of the bolted patch is calculated $\left(\tau_{\text {strength }}\right)$.

Step 5 The average shear stress $\left(\tau_{\text {applied }}\right)$ in the same patch is computed from the elastic finite element analyses. 
Step 6 The "factor of safety" against shearing within each patch is defined as:

$$
\mathrm{FOS}=\tau_{\text {strength }} / \tau_{\text {applied }}
$$

It is required that each patch have a FOS $\geq 1.2$ although it may be found that one or two patches on some joints have lower factors of safety.

\section{Estimating rock mass modulus}

\subsection{Validity of predictions based on classification}

Assessment of rock mass modulus values is critical to the analytical method presented above, and in any problem where an attempt is being made to predict displacements.

In the early years of rock mechanics, prior to 1980, many large-scale, project specific, in situ tests were conducted to measure modulus values. These included pressure chamber tests and large scale plate loading tests. It was also realised, early on, that modulus and in situ stress values could be back figured from tunnel monitoring data (Pells et al., 1981).

Many of these test data were used by Deere and his co-workers to formulate a modulus reduction factor (ratio of mass modulus to substance modulus) as a function of RQD (Bieniawski, 1984).

Nowadays, very many engineers who need a mass modulus value, fire up the free program RocLAB on their computer, assess a GSI value, and accept the computed mass modulus value. The question has to be asked; how reliable are the RocLAB predictions?

To assist in answering this question test results have been collated from direct experience where the author has the raw data and is confident as to the approximately correct mass modulus values. These are compared with values computed from RocLAB.

\subsection{Comparison on measured and predicted values in Hawkesbury Sandstone}

There is a substantial amount of good field experimental data in regard to the mass modulus values of different classes of Hawkesbury Sandstone. Table 1 summarises the field data in comparison with the values computed using the program RocLAB. The data are presented for different classes of Hawkesbury Sandstone, where the class system is described by Pells et al. (1998).

Table 1 Field mass modulus values for Hawkesbury Sandstone

\begin{tabular}{cccc}
\hline Class & GSI & Measured Field Values MPa & RocLAB Prediction MPa \\
\hline I & $\approx 75$ & $1500-2500$ & 21,000 \\
II & $\approx 65$ & $1000-1500$ & 12,000 \\
III & $\approx 55$ & $500-1000$ & 6500
\end{tabular}

Note: Measured field values from: Poulos et al. (1993); Clarke and Pells (2004); Pells et al. (1980); Pells (1990)

It can be seen from the results in Table 1 that the rock mass modulus values for Hawkesbury Sandstone, predicted using RocLab, are too high by about an order of magnitude.

\subsection{Test data from other rock types}

In the early 1970s the author was responsible for a large-scale, double plate bearing test undertaken to determine the mass modulus values for an arch bridge just north of Johannesburg (Figure 6). 

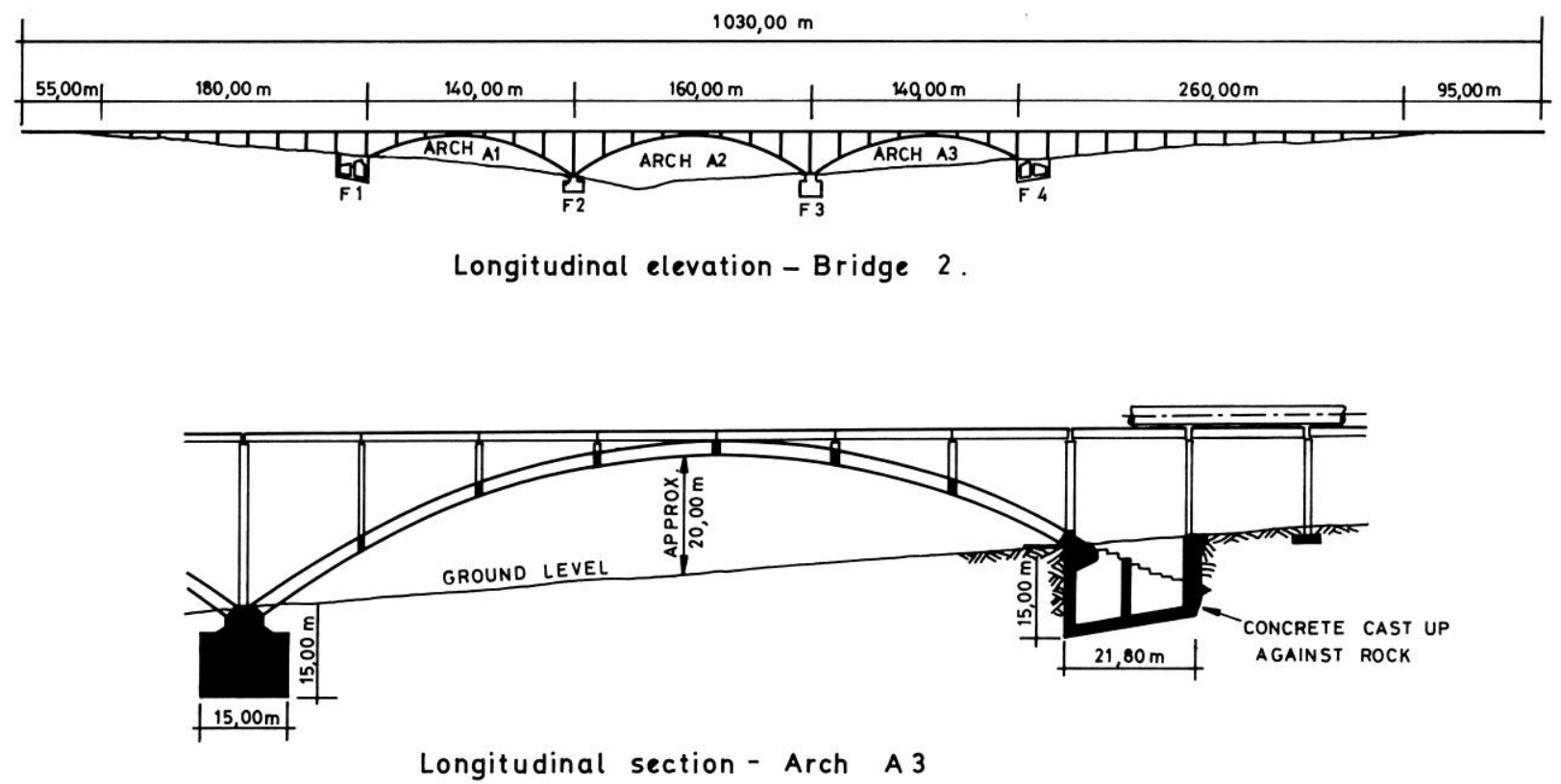

\section{Figure 6 Diepsloot arch bridge}

The layout of the test is shown in Figure 7.

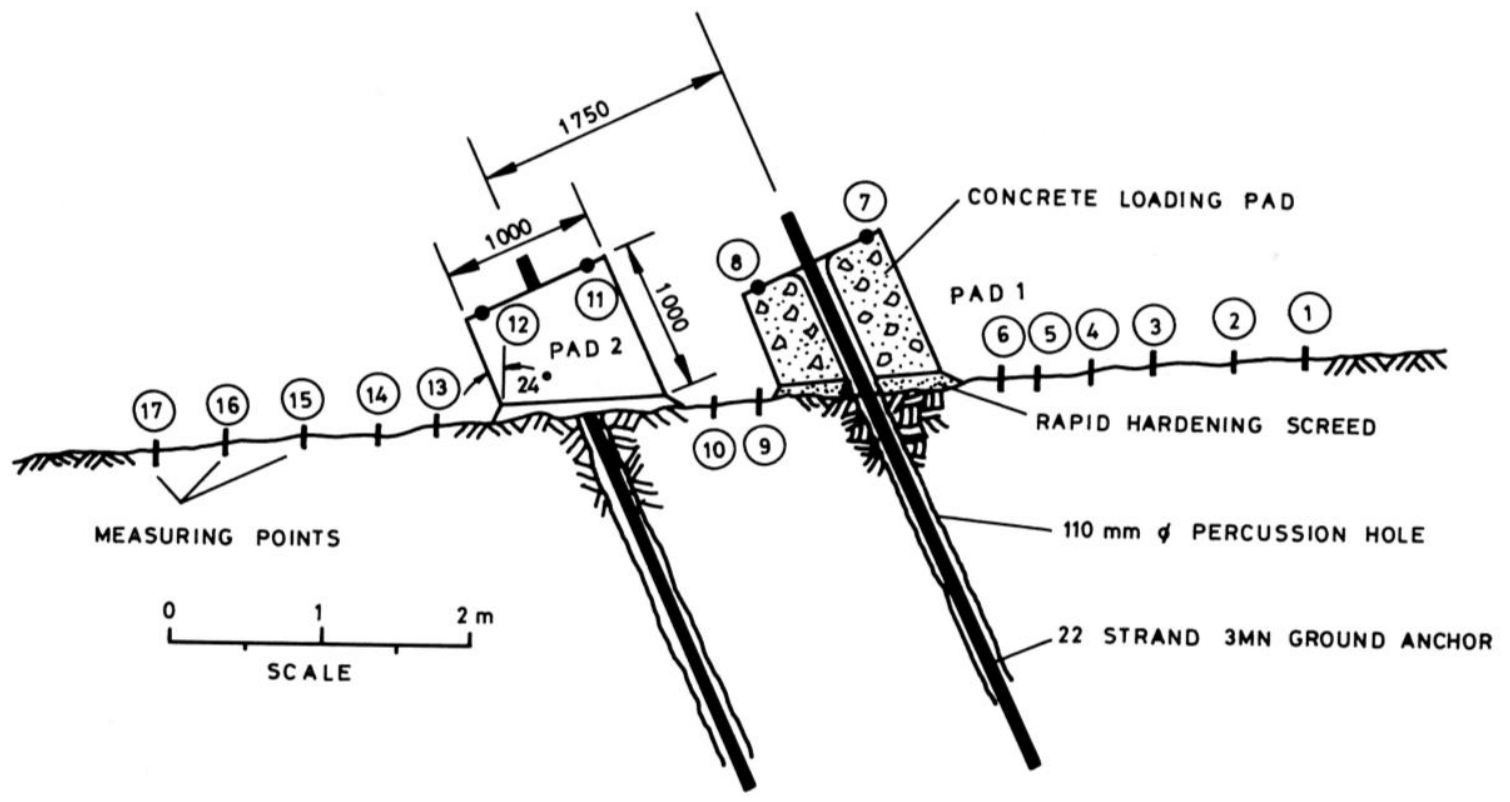

Figure 7 Layout of double cable jacking plate bearing test, with the load oriented in the direction of the bridge reaction

The rock mass comprised weathered granitic gneiss with major inclusions of schist, and numerous pegmatite veins. It was inappropriate to categorise the rock mass on the basis of core data, which was the reason for the in situ test. Tests on core specimens gave UCS values between 12 and $100 \mathrm{MPa}$, with a typical value of about $50 \mathrm{MPa}$. Substance modulus values ranged from 2 to $16 \mathrm{GPa}$.

The load displacement measurements at selected monitoring points, including points on the rock surface, are given in Figure 8. 


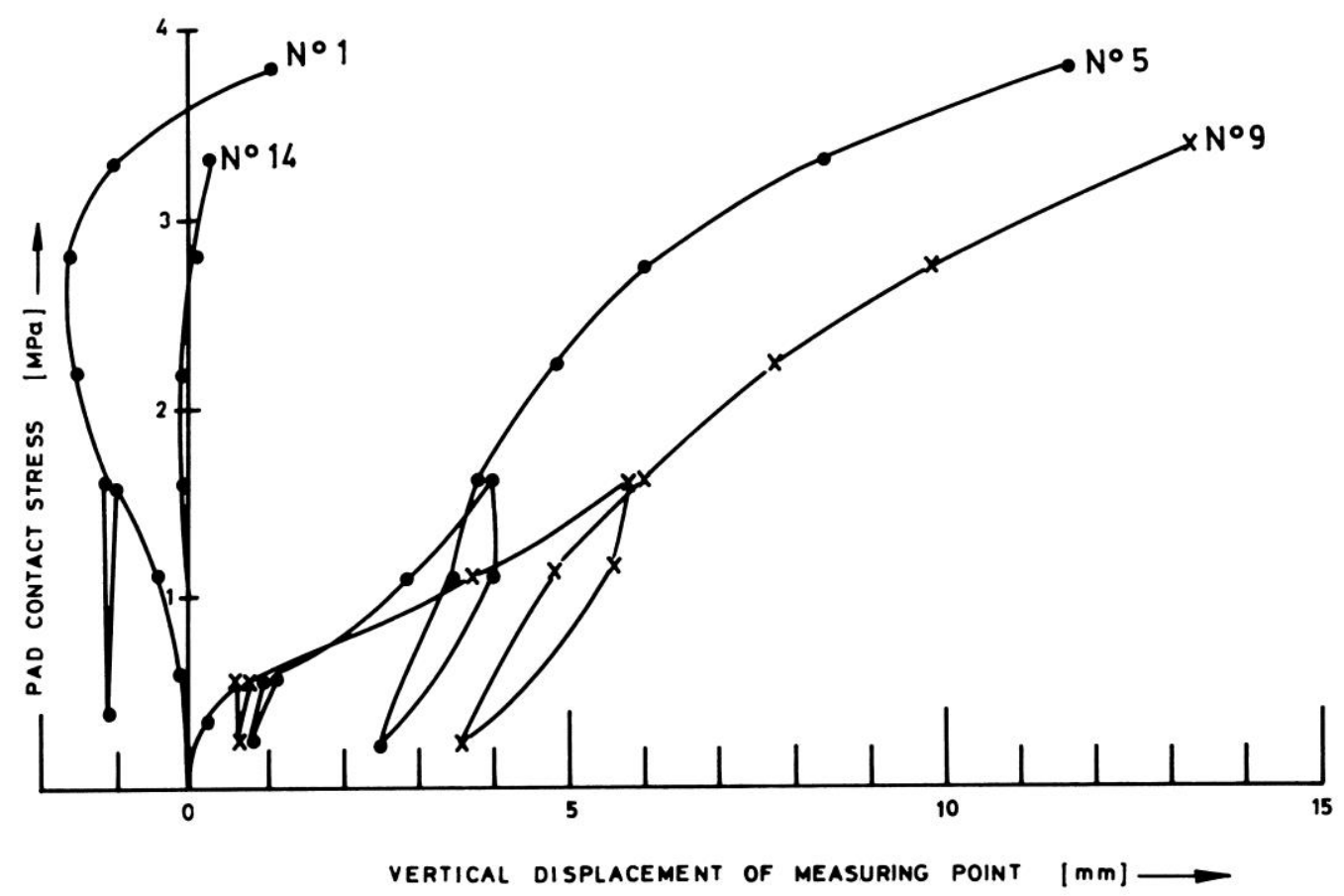

Figure 8 Load displacement results

At an applied bearing pressure of 1.2 MPa the displacement results gave a profile as shown in Figure 9.



Figure 9 Surface Deflections at an Average Applied Bearing Pressure of 1.2 MPa

Figure 9 also shows the theoretical elastic displacements assuming a mass modulus of $600 \mathrm{MPa}$. Comparing the theoretical profile with the measured profile indicates some of the limitations of elastic theory in a closely jointed, poor quality rock mass. Typically, elastic theory predicts a greater spread of displacement that actually occurs in practice. However, leaving aside these limitations it was considered that a mass modulus of $600 \mathrm{MPa}$ provided a reasonable basis for predicting the foundation displacements of the bridge. This proved to be true in practice. 
Turning now to the prediction one would obtain from RocLAB, it would be reasonable to adopt a GSI value of between 25 and 40 and an $m_{i}$ equal to 12. With these values RocLAB gives a predicted mass modulus in the range 700 to $1900 \mathrm{MPa}$. Therefore, in this case, the RocLAB prediction is satisfactory although slightly high.

The second case study is from the Thompson dam in Victoria where a mass modulus was back figured from tunnel monitoring data. The rock comprised highly fractured siltstone. Many of the bedding planes contained crushed, sheared and extremely weathered material. Substance strengths were about $80 \mathrm{MPa}$ with substance modulus values averaging about $60 \mathrm{GPa}$.

Interpretation of the field data (Pells et al., 1981) indicated a mass modulus in the range 1000 to $2000 \mathrm{MPa}$. RocLAB, for GSI $=30, \mathrm{UCS}=50 \mathrm{MPa}$ and $\mathrm{m}_{\mathrm{i}}=7$ gives a mass modulus of $2100 \mathrm{MPa}$. For GSI $=20$, this value drops to $1250 \mathrm{MPa}$. As with the Diepsloot Bridge data, RocLAB gives a good prediction for this case study.

\section{Estimating rock mass strength}

It is very difficult to find case studies from which a reasonably accurate assessment can be made of the shear strength of a rock mass. Two cases that are close to ideal are from cliff failures that occurred in the Sydney Basin associated with full extraction of coal seams near the bases of cliffs. Figure 10 is a photograph of the failure of Dogface Rock at Katoomba, and Figure 11 shows an even larger failure at Nattai North on the edge of Warragamba Dam.

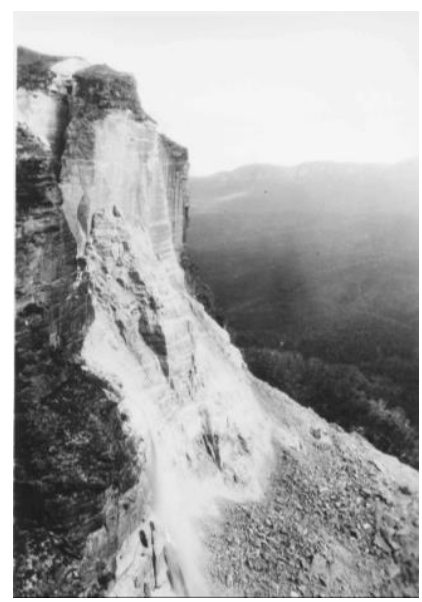

Figure 10 Failure at Katoomba

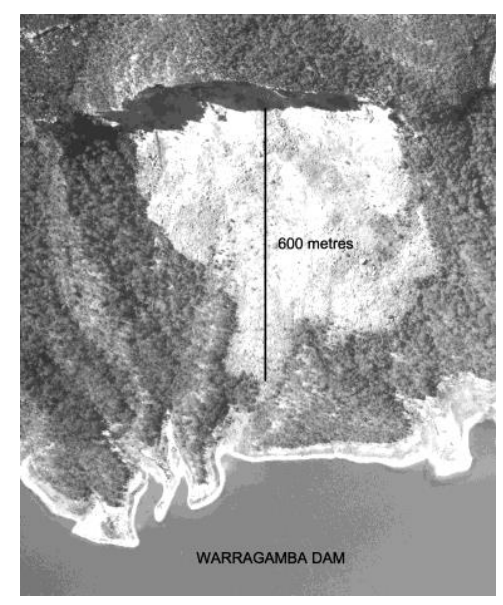

(a) Aerial photo (2006)

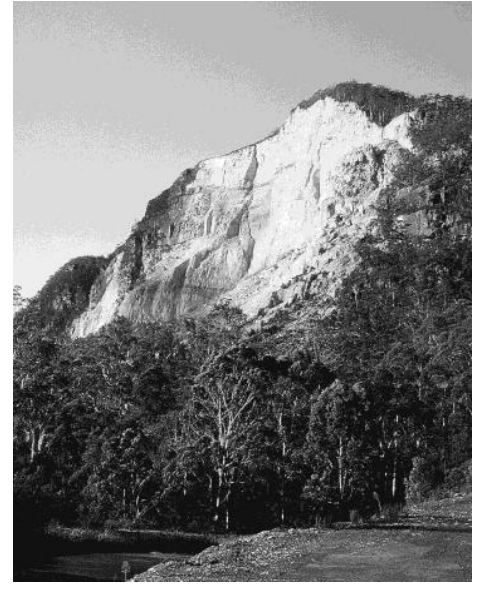

(b) Side view (1981)

Figure 11 Failure at Nattai North 
The failures at both locations were due to total extraction of coal seams, as shown in the simple model in Figure 12. This model was used to assess what macro movements would occur at the cliff face depending upon the location of total extraction. At both Katoomba and Nattai North, extraction occurred directly beneath and on the downslope side of the cliff lines.

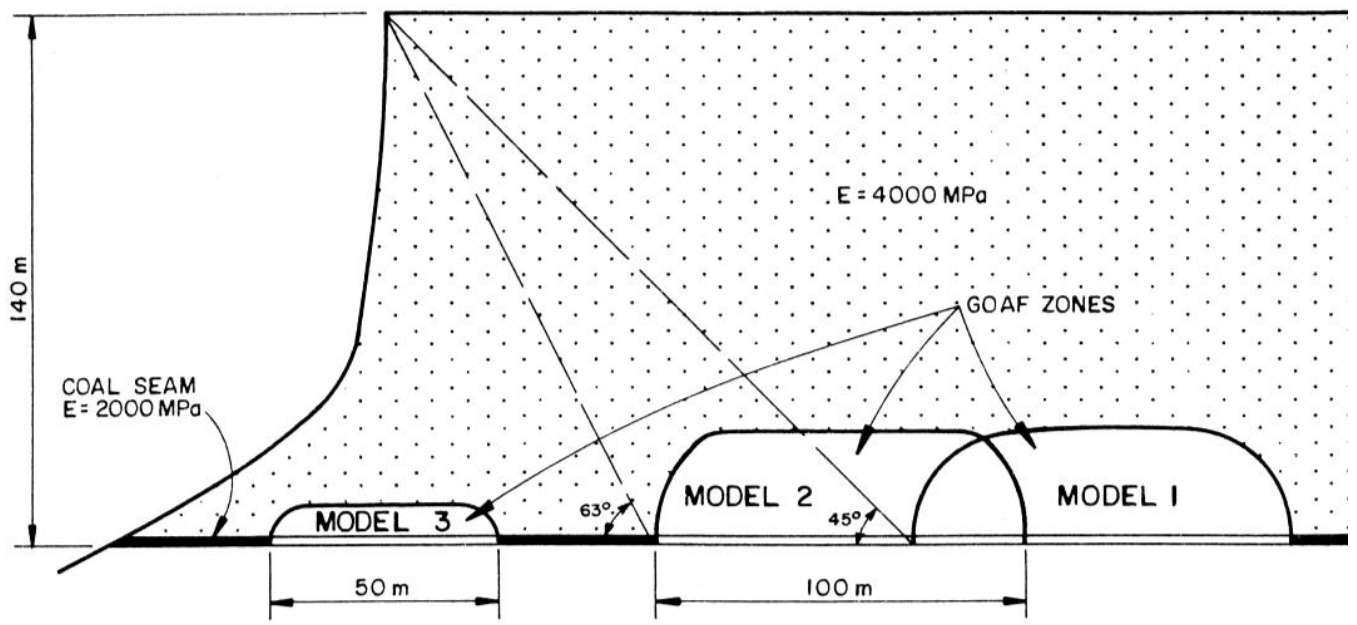

Figure 12 Model used to assess macro impact of mining behind or beneath cliff faces

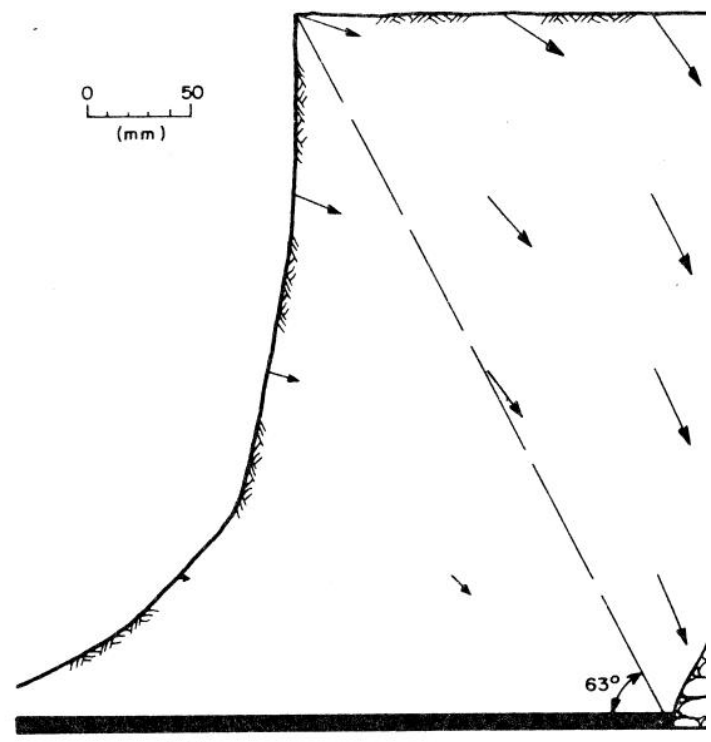

(a)

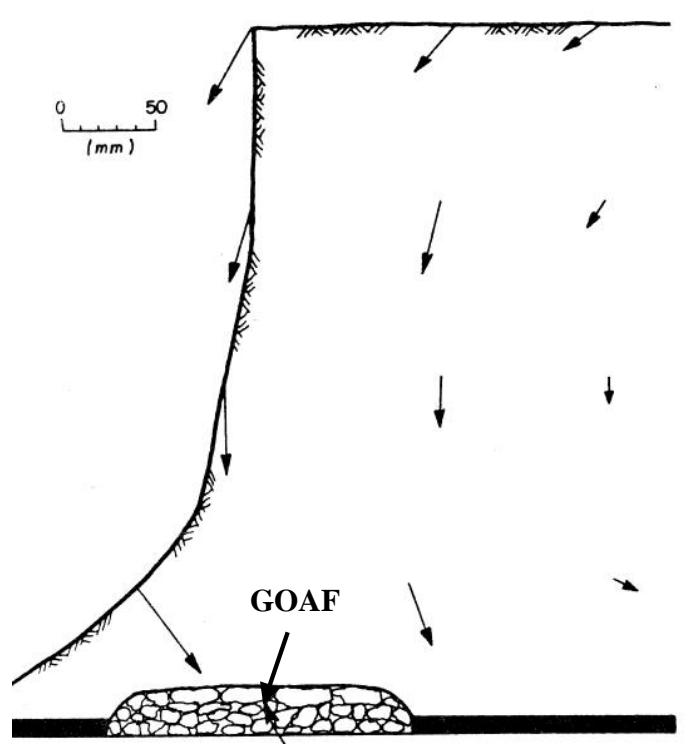

(b)

Figure 13 Predicted cliff movement vectors due to full extraction mining

Figure 13(a) shows displacement vectors where mining occurs well behind the cliff face, and Figure 13(b) shows the vectors when mining occurs beneath the face.

It can be seen from Figure 13(b) that the impact of total extraction directly beneath the cliff line caused the face of a cliff to tilt outwards. This is what was observed at Katoomba, as shown in Figure 10. Unfortunately, there are no available photographs of the initial cracking at Nattai North but antidotal evidence indicates that it comprised the same mechanism as was recorded at Katoomba.

It can be seen from the photograph in Figure 10 that collapse of these cliff faces comprised shearing through the base of a column of sandstone that extended almost the full height of the cliffs. At Katoomba, where the cliff is about $200 \mathrm{~m}$ high, the shearing occurred mainly through the Burra Moko Head Sandstone and partly through the underlying interbedded sandstones and mudstones (Figure 14). 


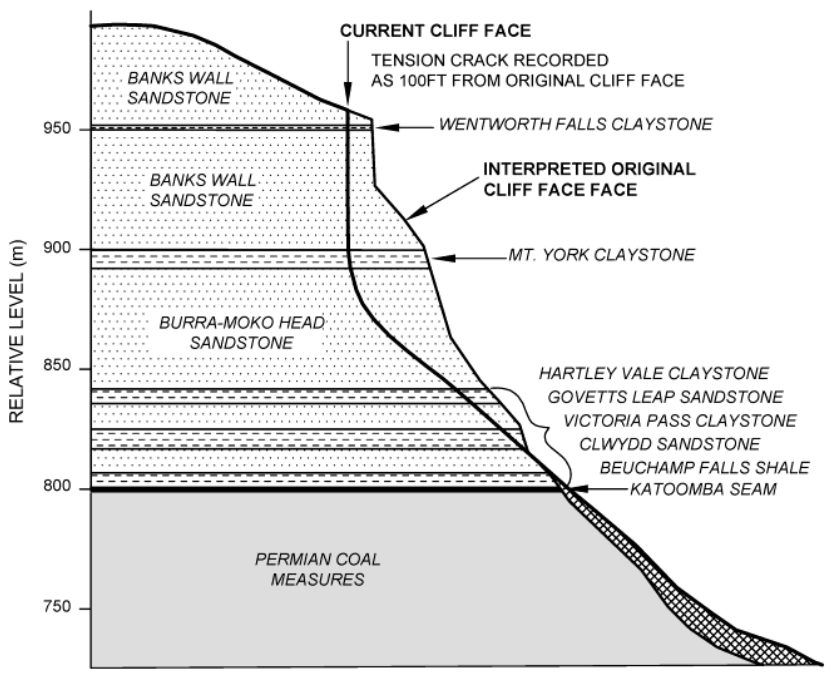

Figure 14 Geology of the cliff failure at Katoomba

There are several ways of analysing these cliff failures. The simplest is to assume that there was, in effect, a massive uniaxial strength failure at the base of the near vertical slabs. Making this simple assumption gives mass uniaxial strengths of about $3 \mathrm{MPa}$ at Nattai North and $5 \mathrm{MPa}$ at Katoomba.

A more sophisticated approach is to attempt to model the failures using numerical analyses and then to back figure the average shear stresses and normal stresses on the shear surface. This approach was done by Helgstedt (1997). His model, and computed displacement vectors are shown in Figure 15.

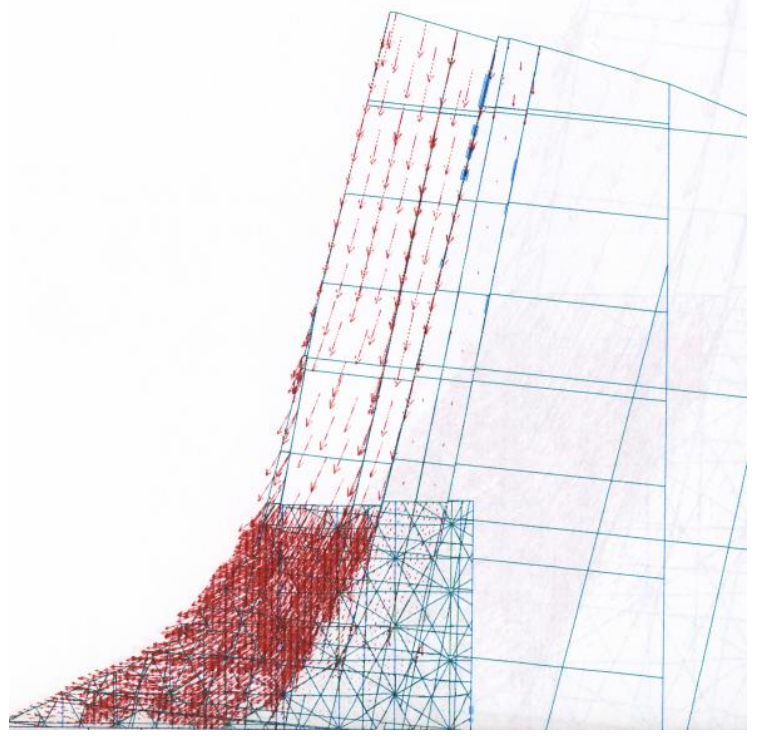

Figure 15 Udec analyses of Nattai North by Helgstedt (1997)

Based on these analyses, Helgstedt (1997) computed:

- Average normal stress equals $2.7 \mathrm{MPa}$.

- Average shear stress equals 2.9 MPa.

These values are equivalent to a UCS $=2.7 \mathrm{MPa}$, which is almost exactly that determined by the trivial hand calculation given earlier.

A third approach is to give cognisance to the fact that within the geological profile at both sites are mudstone horizons of lower shear strength than the massive sandstones. It is possible that the failure mechanism 
involved near horizontal shearing on these mudstone beds, followed by collapse of the sandstone columns. Numerical analyses of the shear stresses on these beds at Nattai North are given in Figure 16.

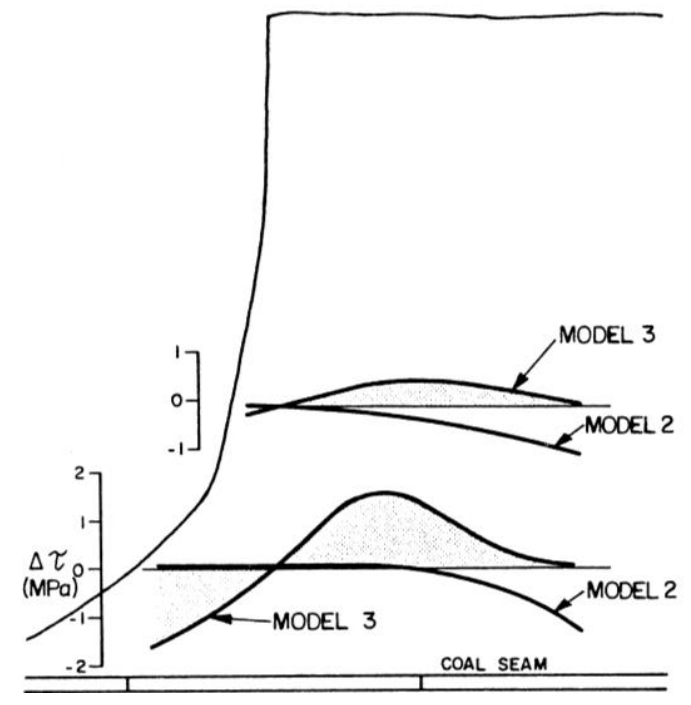

Figure 16 Shear stresses on mudstone horizons at Nattai North

The data in Figure 16 indicate maximum shear stresses of about $1.4 \mathrm{MPa}$ under a normal stress of about $3 \mathrm{MPa}$. This is equivalent to a friction angle of about $25^{\circ}$ which is too low for the fresh mudstone bedding planes. It would be reasonable for horizontal weathered seams which are known to occur in association with the coal measures. However, the shape of the scarp face, as shown in Figure 17, suggests that sliding along horizontal bedding was probably not part of the failure mechanism, and that the simple concept of a massive UCS failure is reasonable.

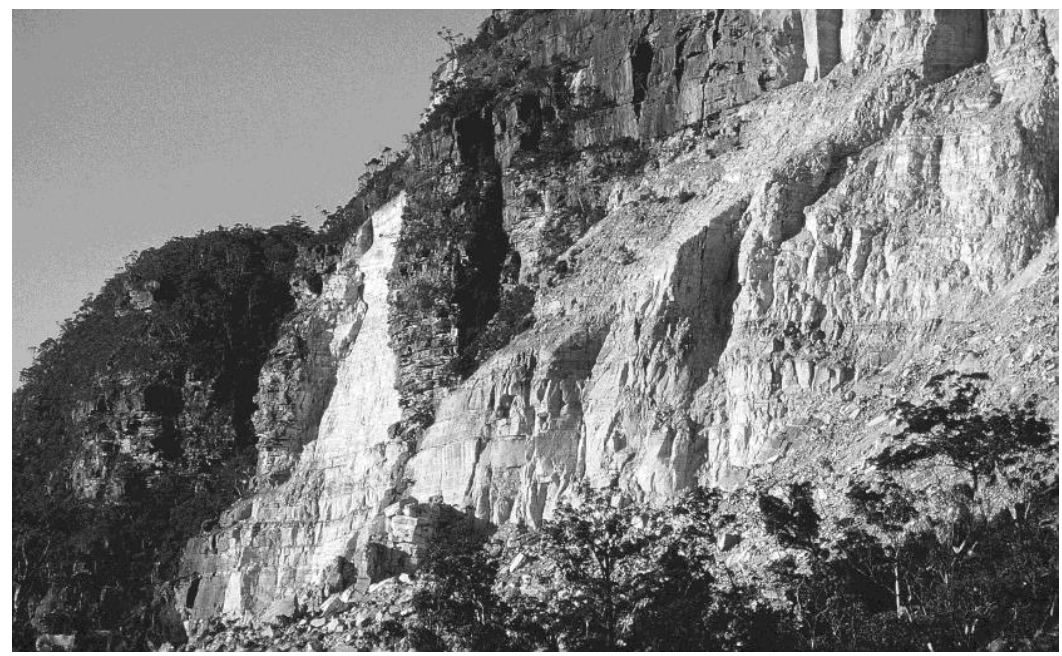

Figure 17 Detail of failure scarp at Nattai North

The hand and UDEC calculated strength values are plotted in Figure 18, which also gives the failure envelope from the Hoek-Brown failure criteria, assuming UCS $=25 \mathrm{MPa}$, GSI $=75$, and $\mathrm{M}_{\mathrm{i}}=17$. The Hoek-Brown criterion predicts a mass UCS of about $10 \mathrm{MPa}$. This is about double the back figured values. 


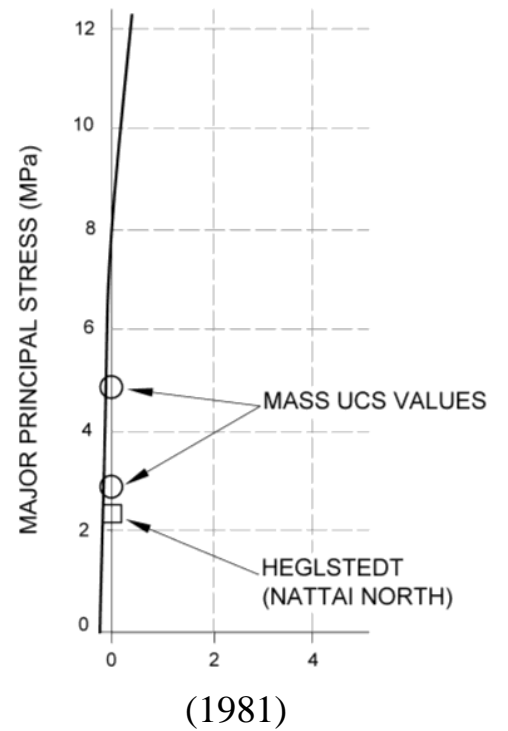

Figure 18 Katoomba and Nattai North data plotted on the Hoek-Brown failure envelope

\section{Conclusions}

The only conclusions that can be reached on the basis of the few case studies presented here is that predictions using the Hoek-Brown failure criterion, work well for some rock types in some situations and poorly for other rock types and other situations. Although the data are insufficient, they do confirm one trend the author has noted over the past years, namely that the classification systems do not seem to work well for relatively low strength, massive porous rock, like Hawkesbury Sandstone. Overall, these are not particularly satisfactory or useful conclusions. However, they do serve as a warning as to blind use of this predictive tool for design parameters.

It is also suggested that it would be very valuable if there could be a workshop symposium wherein all participants were required to bring to the table data they have of rock mass stiffnesses and shear strengths. This may make it possible to determine when the method is satisfactory and when not and may lead to practical guidelines for further developments.

\section{References}

Bieniawski, Z.T. (1984) Rock Mechanics Design in Mining and Tunnelling. Balkema, New York.

Carter, J. (2003) Pells analysis of the shear behaviour of a reinforced rock joint. Report by Advanced Geomechanics, Sydney University.

Clarke, S.J. and Pells, P.J.N. (2004) A large scale cable jacking test for rock mass modulus measurements, Lucas Heights, Sydney. 9th Aust-NZ Geomechanics Conference, Auckland.

Dight, P. (1982) Improvement to the stability of rock walls in open pit mines. PhD Thesis, Monash University.

Evans, W. (1941) The strength of undermined strata. Trans. Inst. Mining and Metallurgy, London, pp. 475-500.

Goodman, R.E. (2007) Geomechanics according to Gunter Riedmüller (1940-2003). Tunnels and tunnelling International, March, pp. 47-49.

Helgstedt, M.D. (1997) An assessment of the in situ shear strength of rock mass and discontinuities. Masters Thesis, University of Lulea.

Palmstrom, A. and Broch, E. (2006) Use and misuse of rock mass classification systems with particular reference to the Q-system. Tunnels and Underground Space Technology, Elsevier, 21, pp. 575-593.

Pells, P.J.N. and Bertuzzi, R. (2008) Discussion on the Paper by Palmstrom and Broch. Tunnels and Underground Space Technology, Elsevier, pp. 340-350.

Pells, P.J.N., McMahon, B.K. and Redman, P.G. (1981) Interpretation of Field Stresses and Deformation Moduli from Extensometer Measurements in Rock Tunnels. 4th Australian Tunnelling Conference, Brisbane, pp. 171-176.

Pells, P.J.N., Mostyn, G. and Walker, B.F. (1998) Foundations on sandstone and shale in the Sydney Region. Australian Geomechanics, No. 33, Part 3, pp. 17-29.

Pells, P.J.N., Rowe, R.K. and Turner, R. (1980) An experimental investigation into side shear for socketed piles in sandstone. Structural Foundations on Rock, Balkeman, pp. 291-302. 
Pells, P.J.N. (1990) Stresses and displacement around deep basements in the Sydney area. The Australian Tunnelling Conference, IE Aust, Sydney, pp. 241-249.

Pells, P.J.N. (2008) What happened to the Mechanics in Rock Mechanics and the Geology in Engineering Geology? 6th Int. Symp. Ground Support, SAIMM, pp. 1-36.

Poulos, H.G., Best, R.J. and Pells, P.J.N. (1993) Load test on instrumented rock socketed pile for new Glebe Island Bridge, Sydney. Australian Geomechanics Journal, 24, p. 97.

Sofianos, A.I. (1996) Analysis and design of an underground hard rock Voussoir beam roof. Int. Jnl. Rock Mechanics and Mining Sciences, Vol. 33, No. 2, pp. 153-166. 